\title{
Mantle $\mathrm{H}_{2} \mathrm{O}$ and $\delta \mathrm{D}$ Associated with Melt Reactions in a Supra-subduction Ophiolite
}

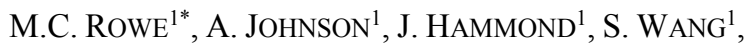
R.L. HERVIG ${ }^{2}$, J.M. WARREN ${ }^{3}$

${ }^{1}$ School of Environment, University of Auckland, Auckland 1010, NZ (*michael.rowe@auckland.ac.nz)

${ }^{2}$ School of Earth and Space Exploration, Arizona State University, Tempe, AZ 85287, USA

${ }^{3}$ Department of Geological Sciences, University of Delaware, Newark, DE 19716, USA

Mantle materials, particularly nominally anhydrous minerals, are recognized as important reservoirs for $\mathrm{H}_{2} \mathrm{O}$ on Earth. Water in these materials represents a control on mantle properties and processes, including viscosity and melt productivity. We propose that melt channelization and infiltration, preserved in ophiolite mantle sections, serve as a pathway for volatile enrichment and fractionation, through hydrogen diffusion and melt crystallization in the Earth's upper mantle. Melt pathways are preserved as dunite and pyroxenite bodies within mantle peridotite. Here we examine $\mathrm{H}_{2} \mathrm{O}$ and hydrogen isotopic variations, and associated major and trace element abundances, in clinopyroxene and orthopyroxene of the Trinity Ophiolite (USA), sampled from transects perpendicular to lithologic contacts within the peridotite.

Results from four transects are associated with: a large and small clinopyroxenite vein, a large dunite body, and a small dunite channel. Hydrogen and ${ }^{2} \mathrm{H}$ were measured as negative ions, with a $\mathrm{Cs}^{+}$ion source on a Cameca of SIMS at ASU. Serpentine and other alteration minerals have variably overprinted these materials, resulting in localized enrichments in pyroxene water contents of up to $2600 \mathrm{ppm}$. Despite sporadic high $\mathrm{H}_{2} \mathrm{O}$ contents, most pyroxenes range from 180$580 \mathrm{ppm}$ with a median $\mathrm{H}_{2} \mathrm{O}$ of $487 \mathrm{ppm}$. Within this group, $\delta \mathrm{D}$ varies from $\sim 66$ to $-222 \%$ (median of $-104 \%$ ) with much of the isotopic range overlapping for all study sites, despite differences in $\mathrm{H}_{2} \mathrm{O}$ content. Adjacent to larger dunite and pyroxenite bodies, water contents in pyroxene are enriched (volatile movement into the peridotite). However, no systematic variations are observed adjacent to smaller features, suggesting either minimal volatile movement, or sufficient time for diffusive re-equilibration. We observe a good correlation between $\delta \mathrm{D}$ and $\mathrm{H}_{2} \mathrm{O}$ content in clinopyroxene but not orthopyroxene. We use major and trace element compositions of pyroxenes to assess the nature of $\mathrm{H}$ rich fluid addition/subtraction and the potential influence of late stage serpentinization. 